\title{
Changes in membrane glycoproteins of circulating platelets after coronary stent implantation
}

\author{
M Gawaz, F J Neumann, I Ott, A May, S Rüdiger, A Schömig
}

\begin{abstract}
Objectives-To evaluate platelet function in patients with coronary stents.

Design-A non-randomised control trial in 30 patients who had immediate implantation of Palmaz-Schatz coronary stents because of a suboptimal angioplasty result. All patients received a standardised anticoagulation regimen including intravenous heparin (activated partial thromboplastin time (APTT) 80 to $120 \mathrm{~s}$ ), oral vitamin $\mathrm{K}$ antagonist (target international normalised ratio (INR) of $3.5)$, and $100 \mathrm{mg}$ aspirin twice daily. Platelet surface expression of glycoprotein IIb-IIIa, activated fibrinogen receptor, and P-selectin as well as binding of von Willebrand factor and fibrinogen were determined by flow cytometry in peripheral venous blood samples collected before the intervention and then daily for 4 days after it. The results were compared with those in $\mathbf{3 0}$ patients undergoing elective coronary balloon angioplasty.
\end{abstract}

Setting-University hospital.

Results-After coronary stenting surface expression of the activated fibrinogen receptor significantly increased, peaking at day $2(P<0.001)$. Similar results were found for von Willebrand factor binding and $P$-selectin surface expression, with a maximum at day 2 to 4 after stenting (von Willebrand factor, $P<0.001$; P-selectin, $P<0.001)$. The changes in platelet membrane glycoproteins coincided with a significant drop in peripheral platelet count after stent placement $(P<0.01)$. No significant change in fibrinogen receptor activity, von Willebrand factor binding, P-selectin surface expression, or platelet count was seen in the control group.

Conclusions-The present study shows that current anticoagulation treatment is inefficient in suppressing platelet activation in patients with coronary stents and, therefore, might not be the best treatment for reducing the incidence of subacute stent thrombosis.

(Heart 1996;76:166-172)

Keywords: angioplasty, coronary stent implantation, platelets, membrane glycoproteins

Coronary stenting is an effective method to treat abrupt vessel closure after coronary bal- loon angioplasty (PTCA). ${ }^{1-5}$ Subacute stent thrombosis, however, is a major complication after stent placement and occurs in about 3\% to $21 \% .^{1-3}$ 6-10 Thus strict antithrombotic regimens are used in stent patients to prevent thrombotic events, at the cost of increased bleeding complications. ${ }^{6-811}$ Platelet adhesion and aggregation play a fundamental role in acute coronary thrombus formation ${ }^{12}{ }^{13}$; however, platelet function in coronary stent patients has not been evaluated.

Platelet adhesion and aggregation depend on the exposure of adhesive glycoproteins on the platelet surface ${ }^{1415}$ and these mechanisms are the target of newer antiplatelet drugs. ${ }^{16} 17$ Vascular injury - as it occurs after dilatation and stenting of atherosclerotic lesionsexposes circulating blood to potentially thrombogenic surfaces on the subendothelium. ${ }^{13}$ Platelets can then adhere to the injured vessel wall through interaction with immobilised von Willebrand factor (vWF). ${ }^{18}$ After they adhere, platelets become activated and induce fibrinogen $(\mathrm{fg})$ binding sites on the glycoprotein complex IIb-IIIa. ${ }^{19} 20$ Plasma fibrinogen can then bind to the activated platelet surface and initiate aggregation and thrombus formation through interplatelet bridging. ${ }^{1920}$ Concomitantly, platelets degranulate and redistribute granule-stored glycoprotein $\mathrm{P}$-selectin (GMP-140, PADGEM) to their surface; this mechanism supports haemostatic consolidation of the thrombotic plug. ${ }^{21}$

The present study focuses on changes in platelet membrane glycoproteins after coronary stenting. Immunological detection of platelet surface glycoproteins allows a spectrum of specific activation-dependent modifications in the glycoprotein composition of the platelet membrane to be detected with a high degree of sensitivity. ${ }^{22}$ Several studies of extracorporal blood bypass, ${ }^{24}$ coronary angioplasty, ${ }^{25-27}$ or multiple organ failure, ${ }^{28}$ have shown this method to be a useful tool for assessing prethrombotic states in clinical settings. We studied the hypothesis that platelet function is altered after coronary stent placement by comparing the results with those in a group of patients undergoing elective coronary angioplasty (PTCA).

Patients and methods

STUDY POPULATION

All patients studied had a high-grade coronary artery stenosis $(>80 \%)$ and a positive exercise test. Platelet function was investigated in 30 patients who had had a Palmaz-Schatz stent 
implanted immediately after angioplasty. The results were compared with 30 patients who had successful angioplasty without angiographically detectable dissection. Written informed consent to coronary stenting and for the repeated collection of blood was obtained from all patients before the intervention. The study was performed after the protocol was approved by the ethics committee of our university.

The basic characteristics and a summary of laboratory variables are shown in tables 1 and 2. Patients were excluded if they had a recent myocardial infarction, unstable angina, or any illness known to influence platelet function including chronic inflammatory disease, active bleeding, severe anaemia, or chronic renal failure. All patients were on long term aspirin treatment before entering the study.

\section{STUDY DESIGN}

Balloon angioplasty was performed identically in both groups by the transfemoral approach. After initial coronary angiography, 15000 international units of unfractionated heparin (Thrombophob, Nordmark, Germany) and $500 \mathrm{mg}$ of aspirin (Aspisol, Bayer, Germany) were given intravenously just before the catheter system was inserted. None of the patients received any thrombolytic treatment throughout the procedure or thereafter. The decision to implant a stent was made as

Table 1 Clinical data on study patients

\begin{tabular}{|c|c|c|}
\hline & $\begin{array}{l}\text { Stent group } \\
(n=30)\end{array}$ & $\begin{array}{l}\text { PTCA group } \\
(n=30)\end{array}$ \\
\hline Gender (M/F) & $24 / 6$ & $23 / 7$ \\
\hline $\begin{array}{l}\text { Age (y) (mean (SD), range) } \\
\text { Number of diseased vessels (n) (\%): }\end{array}$ & $57(9 \cdot 6)(39-82)$ & $61(8 \cdot 4)(47-80)$ \\
\hline \multicolumn{3}{|l|}{ Number of diseased vessels (n) (\%): } \\
\hline 1 & $13(43 \cdot 3)$ & $15(50 \cdot 0)$ \\
\hline 2 & $10(33 \cdot 3)$ & $10(33 \cdot 3)$ \\
\hline 3 & $7(23 \cdot 4)$ & $5(16 \cdot 7)$ \\
\hline Single stent $(\mathrm{n})(\%)$ & $23(76 \cdot 7)$ & - \\
\hline Multiple stent (n) (\%) & $7(23 \cdot 3)$ & - \\
\hline Balloon size (mm) (mean (SD), range) & $3 \cdot 27(0 \cdot 3)(3 \cdot 0-4 \cdot 0)$ & $2 \cdot 98(0 \cdot 4)(2 \cdot 5-4 \cdot 0)$ \\
\hline \multicolumn{3}{|l|}{ Target vessel $(\mathrm{n})(\%)$ : } \\
\hline LAD & $13(43 \cdot 3)$ & $16(53 \cdot 3)$ \\
\hline $\mathrm{LCx}$ & $2(6 \cdot 7)$ & $8(26 \cdot 7)$ \\
\hline $\mathrm{RCA}$ & $13(43 \cdot 3)$ & $4(13 \cdot 3)$ \\
\hline Bypass & $2(6 \cdot 7)$ & $2(6 \cdot 7)$ \\
\hline History of myocardial infarction (n) (\%) & $14(46 \cdot 7)$ & $13(43 \cdot 3)$ \\
\hline Prior PTCA (n) (\%) & $11(36 \cdot 7)$ & $9(30 \cdot 0)$ \\
\hline \multicolumn{3}{|l|}{ Coronary risk factors $(\mathrm{n})(\%)$ : } \\
\hline Hypercholestolaemia & $23(76 \cdot 7)$ & $24(80 \cdot 0)$ \\
\hline Systemic hypertension & $18(60.0)$ & $12(40 \cdot 0)$ \\
\hline Active smoking & $12(40 \cdot 0)$ & $8(26 \cdot 7)$ \\
\hline Diabetes & $4(13 \cdot 3)$ & $7(23 \cdot 3)$ \\
\hline Reduced LV function (ejection fraction $<50 \%$ ) & $8(26 \cdot 7)$ & $8(26 \cdot 7)$ \\
\hline
\end{tabular}

$\mathrm{LAD}$, left anterior descending coronary artery; LCx, left circumflex coronary artery; RCA, right coronary artery; PTCA, percutaneous transluminal coronary angioplasty; RCA, right coro
$\mathrm{LV}$, left ventricle.

Table 2 Laboratory variables of study patients

\begin{tabular}{|c|c|c|}
\hline Variable & $\begin{array}{l}\text { Stent group } \\
(n=30)\end{array}$ & $\begin{array}{l}\text { PTCA group } \\
(n=30)\end{array}$ \\
\hline WBC $\left(\times 10^{3} / \mathrm{ml}\right)$ & $9 \cdot 19(3.00)$ & $8.90(4 \cdot 07)$ \\
\hline Haemoglobin $(\mathrm{g} / \mathrm{dl})$ & $13.42(0.99)$ & $12 \cdot 80(1 \cdot 31)$ \\
\hline Platelet count $\left(\times 10^{3} / \mathrm{ml}\right)$ & $232 \cdot 73(65 \cdot 13)$ & $227.55(54 \cdot 20)$ \\
\hline Creatinine (mg/dl) & $0.97(0.37)$ & $0.94(0.14)$ \\
\hline Urea $(\mathrm{mg} / \mathrm{dl})$ & $16 \cdot 65(6.33)$ & $11.83(1.95)$ \\
\hline GPT (U/1) & $24.05(17.09)$ & $15 \cdot 80(5 \cdot 14)$ \\
\hline $\mathrm{AP}(\mathrm{U} / \mathrm{l})$ & $115.50(56.18)$ & $101.00(20.52)$ \\
\hline Bilirubin (mg/dl) & $0.65(0.30)$ & $0.60(0 \cdot 26)$ \\
\hline $\mathrm{CK}(\mathrm{U} / \mathrm{l})$ & $35 \cdot 16(35 \cdot 29)$ & $22.50(9 \cdot 48)$ \\
\hline
\end{tabular}

WBC, white blood cell count;
phosphatase; CK, creatine kinase. described recently. ${ }^{5}$ Within the first four hours after the intervention we removed the arterial sheath in both study groups, as soon as the APTT fell below $80 \mathrm{~s}$.

All patients were given two $100 \mathrm{mg}$ aspirin tablets on the day of the intervention and then daily thereafter. In patients undergoing balloon angioplasty (PTCA) anticoagulation with intravenous heparin (APTT 60 to 90 seconds) was stopped after 24 hours. Immediately after coronary stenting an oral vitamin $\mathrm{K}$ antagonist (Marcumar, Hoffmann-La Roche) was started and intravenous heparin was continued to adjust APTT values of $80-120 \mathrm{~s}$ until a target prothrombin time of 3.5 (INR) was achieved.

\section{SPECIMEN COLLECTION}

Peripheral venous blood samples were taken with a loose tourniquet through a short venous catheter inserted into a forearm vein just before and then daily in the morning after coronary intervention. A multiple-syringe sampling technique was used and the first $2 \mathrm{ml}$ of blood were discarded. Thereafter, $2.5 \mathrm{ml}$ of blood collected in disodium ethylenediaminetetra-acetic acid (EDTA) was used to measure the platelet and white blood cell count, haemoglobin, and hematocrit with a Coulter Counter (Corning). Four ml of blood was collected in $3.8 \%$ citrate to measure coagulation variables and $5 \mathrm{ml}$ was taken for serum chemistry. For flow cytometric analysis $1.6 \mathrm{ml}$ blood was collected into a polypropylene syringe containing $0.4 \mathrm{ml}$ of citrate phosphate dextrose acid adenine (CPDA).

PREPARATION OF SAMPLES FOR FLOW

CYTOMETRIC ANALYSIS

Preparation of platelets and immunolabelling of platelets with monoclonal antibodies $(\mathrm{mAb})$ for flow cytometric analysis was performed as described previously. ${ }^{28-32}$ In brief, immediately after blood collection CPDA-anticoagulated whole blood was centrifuged at $50 \mathrm{~g}$ for 10 min to obtain platelet-rich plasma (PRP). Thereafter, $5 \mathrm{ml}$ of PRP was added to polypropylene tubes (Becton-Dickinson) preleoaded with $45 \mathrm{ml}$ of modified HEPESTyrode's buffer containing saturating concentrations of fluorescein-isothiocyanate (FITC)conjugated mAbs. Non-specific membrane immunofluorescence was determined by use of an irrelevant FITC-IgG mAb. Samples were incubated in the dark for $15 \mathrm{~min}$ at room temperature without agitation. Immunolabelled samples were fixed by addition of $1 \mathrm{ml}$ $0.5 \%$ paraformaldehyde in phosphate buffered saline, $\mathrm{pH} 7 \cdot 4$, and stored at $4^{\circ} \mathrm{C}$ until flow cytometry was performed within 24 hours. The platelet assay we used gives reproducible results without significant artefactual platelet activation and is suitable for platelet analysis in various clinical settings. ${ }^{28-33}$

\section{FLOW CYTOMETRY OF PLATELETS}

Platelet samples were run on a FACScan cytometer (Becton Dickinson) equipped with a $2 \mathrm{~W}$ coherent argon-ion laser with an excitation wavelength set at $488 \mathrm{~nm}$. The flow cytometer was calibrated with commercially 
Figure 1 Role of membrane glycoproteins in platelet function. Under physiological conditions platelets circulate in a resting state. Activation exposes fibrinogen binding sites on the glycoprotein complex IIb-III that allow plasma fibrinogen to allow plasma fibrinogen to
bind to the platelet surface. Fibrinogen bridging between platelets initiates the aggregation process. Thereafter, platelets degranulate and $\alpha$-granule glycoprotein GMP-140 (P-selectin) is expressed on their surface. von Willebrand factor binds to two distinct glycoprotein complexes, GPIb and GPIIb-III a, present on the platelet surface and is crucial for platelet adhesion to subendothelium. Use of a panel of $m A b s$ that recognise specific glycoproteins (anti-CD41, anti-LIBS1, anti-CD62P, anti-fg, anti-vWF) identifies the functional state of circulating platelets.

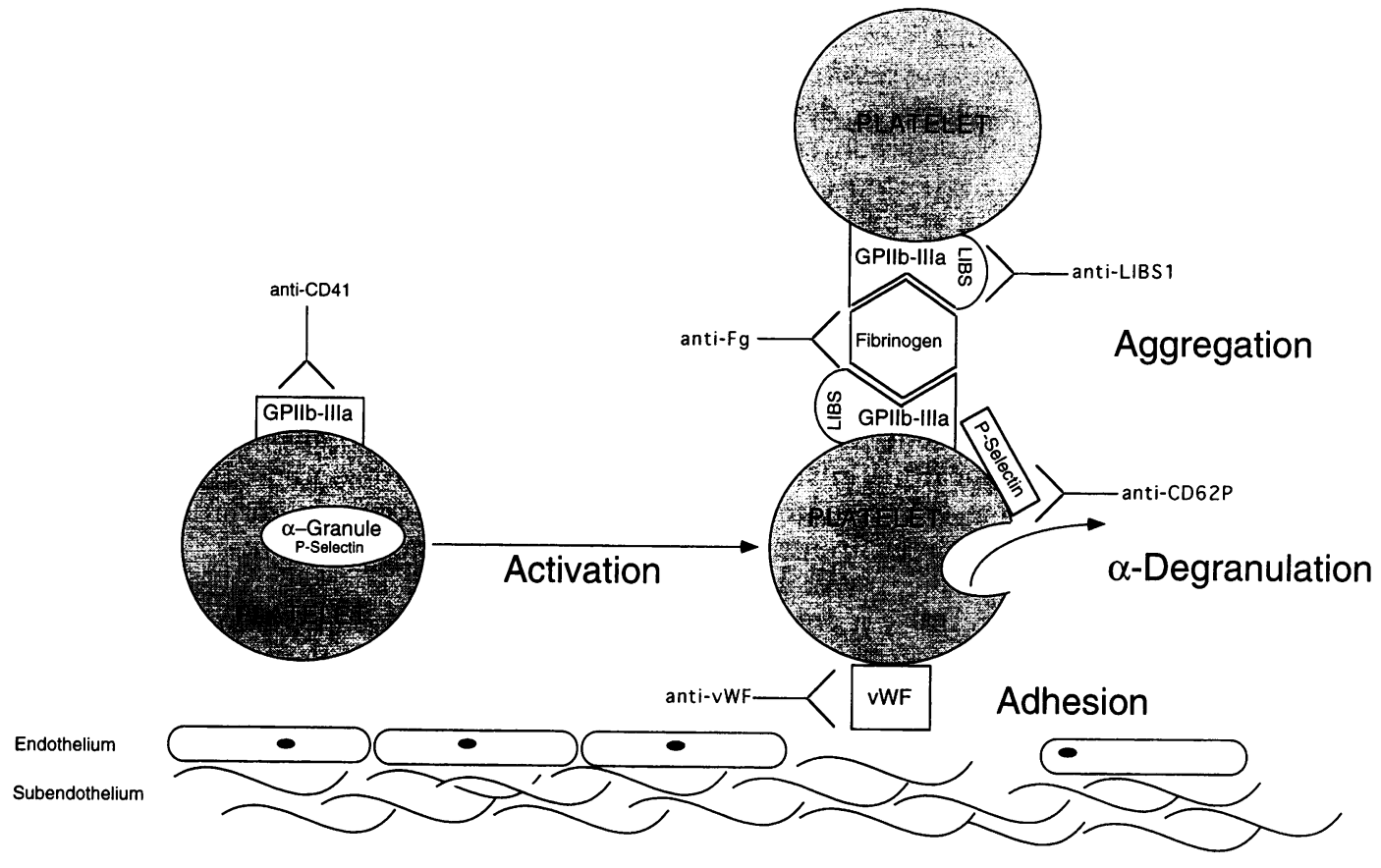

available standard fluorescent microbeads (Calibrite, Becton-Dickinson). Fluorescence and light scatter data were supplied in logarithmic mode and platelets were identified by means of their characteristic size and granularity in the forward versus right angle light scatter plot. For immunofluorescence analysis a narrow gate was set around the platelet population to exclude red cells and cell fragments or background machine noise as described. ${ }^{29}$ Samples were analysed at a flow rate of 200 to 300 events per second and a total of 5000 events was acquired and analysed using the FACScan scientific program (BectonDickinson). Platelet antigen expression was expressed as relative mean particle fluorescence intensity of total platelet population (GPIIb-IIIa) or as percentage of marker positive platelets (LIBS1, CD62, fg, vWF). The platelet population evaluated was found to be $>98 \%$ positive for the platelet-specific CD41 antigen.

\section{MONOCLONAL ANTIBODIES}

All mAbs used in this study were either commercially obtained as FITC-conjugates or were labelled with the fluorescent dye according to standard methods. Anti-CD41 (Dianova, Hamburg) is raised against the glycoprotein complex IIb-IIIa and detects the receptor in its resting or activated forms. AntiLIBS1 mAb (generously provided by Dr Mark Ginsberg, Scripps Clinic, La Jolla, CA) recognises a cryptic epitope on GPIIIa that becomes Willebrand factor and was used to determine
Table 3 Procedural characteristics and angiographic results (mean (SD))

\begin{tabular}{lccl}
\hline Measurement & Stent group & $P T C A$ group & $P^{\star}$ \\
\hline Reference diameter (mm) & $3.07(0.56)$ & $2.73(0.47)$ & 0.017 \\
Minimal lumen diameter before (mm) & $0.86(0.41)$ & $0.81(0.43)$ & 0.603 \\
Minimal lumen diameter after (mm) & $3.16(0.46)$ & $2 \cdot 14(0.55)$ & 0.001 \\
Diameter stenosis before (\%) & $70.79(15.62)$ & $70.85(13.79)$ & 0.848 \\
Diameter stenosis after (\%) & $13.81(6.23)$ & $25.02(11.76)$ & 0.001 \\
Balloon/vessel ratio & $1.09(0.32)$ & $1.09(0.28)$ & 0.212 \\
\hline
\end{tabular}

^Differences between the two treatment groups. exposed only on the activated and ligandoccupied GPIIb-IIIa complex. ${ }^{33}$ Thus antiLIBS1 binding indicates fibrinogen receptor activity on the platelet surface. Anti-fg mAb recognises the E-fragment of the fibrinogen molecule and was used to detect fg molecules bound to the activated platelet surface. AntivWF $\mathrm{mAb}$ is directed against human von von Willebrand factor bound to platelets. Anti-CD62P recognises the $\alpha$-granule membrane glycoprotein P-selectin (GMP-140, PADGEM) that is exclusively expressed on the surface of activated platelets ${ }^{15}$ and was used as marker for $\alpha$-degranulation. The antigens determined in the present study and the physiological significance of platelet membrane glycoproteins for platelet function are summarised in figure 1.

\section{STATISTICAL ANALYSIS}

To test for differences between values obtained before and then daily after the intervention we used non-parametric tests (Friedman test followed by Wilcoxon rank sum test). Data are presented in tables as median $(25,75$ th quartile) for $\mathrm{N}$ observations. In the figures data are presented as line graphs showing medians and quartiles.

\section{Results \\ PATIENTS}

Between January and May 1994, 30 patients undergoing balloon angioplasty and 30 patients that were treated with coronary stent implantation were studied. Both groups of patients had similar basic demographic characteristics and laboratory variables (tables 1 and 2). In all patients angioplasty of the stenosed artery was successful, resulting in a significant reduction in residual stenosis without angiographically detectable dissection (table 3). Minimal lumen diameter before, 
Table 4 Medication given before and after intervention

\begin{tabular}{|c|c|c|c|c|}
\hline \multirow[b]{2}{*}{ Medication } & \multicolumn{2}{|l|}{ Before } & \multicolumn{2}{|l|}{ After } \\
\hline & $\begin{array}{l}\text { Stent group } \\
(n=30)\end{array}$ & $\begin{array}{l}\text { PTCA group } \\
(n=30)\end{array}$ & $\begin{array}{l}\text { Stent group } \\
(n=30)\end{array}$ & $\begin{array}{l}\text { PTCA group } \\
(n=30)\end{array}$ \\
\hline \multicolumn{5}{|l|}{ Antithrombotics: } \\
\hline Aspirin & 26 & 27 & 29 & 30 \\
\hline Ticlopidine & 1 & - & 1 & - \\
\hline Unfractionated heparin & - & - & $\begin{array}{l}30 \text { (14 } 000 \text { to } \\
43000 \mathrm{IU} / \text { day) } \\
\text { until target } \\
\text { INR } 3 \cdot 5\end{array}$ & $\begin{array}{l}30(19000 \text { to } \\
38000 \mathrm{IU} / \text { day }) \\
\text { for } 24 \text { hours }\end{array}$ \\
\hline \multicolumn{5}{|l|}{ Anti-anginal medication: } \\
\hline $\begin{array}{l}\beta \text {-receptor blockers } \\
\text { Nitrates (long-acting) }\end{array}$ & 24 & $\begin{array}{l}25 \\
23\end{array}$ & 29 & 28 \\
\hline
\end{tabular}

None of the differences between the two groups reached statistical significance ( $P>0.05)$.

Figure 2 Fibrinogen receptor function on circulating platelets in patients undergoing stent placement and PTCA. Graphs show surface expression of GPIIb-IIIa complex and of the activated fibrinogen receptor, and show fibrinogen binding on circulating platelets in patients after coronary stent implantation $(n=$ 30) (O) or balloon angioplasty $(n=30)$ (O). The relative mean intensity of

immunofluorescence is shown and was used as measure of $m A b$ binding and glycoprotein surface expression. An asterisk indicates significance compared with starting values before intervention (bound fibrinogen day 1 to $3, P<0.001$; day 4 P $<0.01$ : activated fibrinogen receptor day 2 and $3, P<0.01$ ).
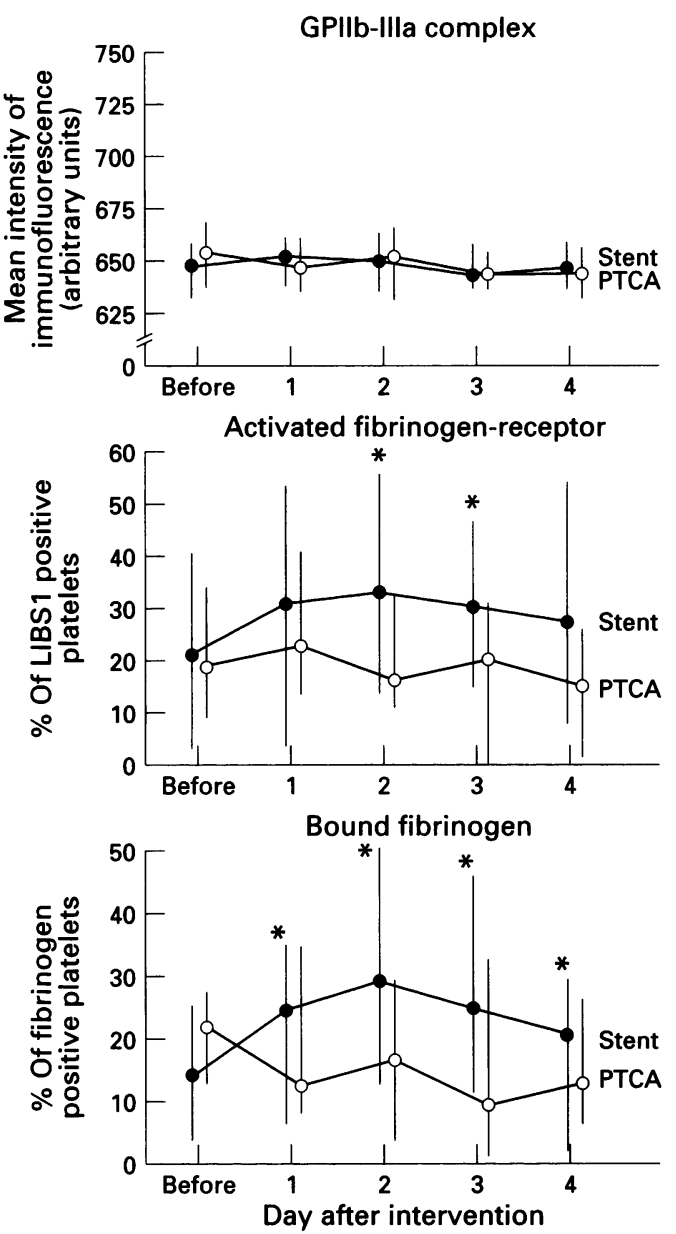

Figure 3 von Willebrand factor binding to circulating platelets in patients undergoing stent placement and PTCA. Graphs show binding of Graphs show binding of
von Willebrand factor to circulating platelets in patients after coronary stent implantation ( $n=$ 30) (O) or elective balloon angioplasty $(n=$ 30) (○). An asterisk indicates significance compared with starting values before intervention (day 1 to $4 ; P<0.01$ ).

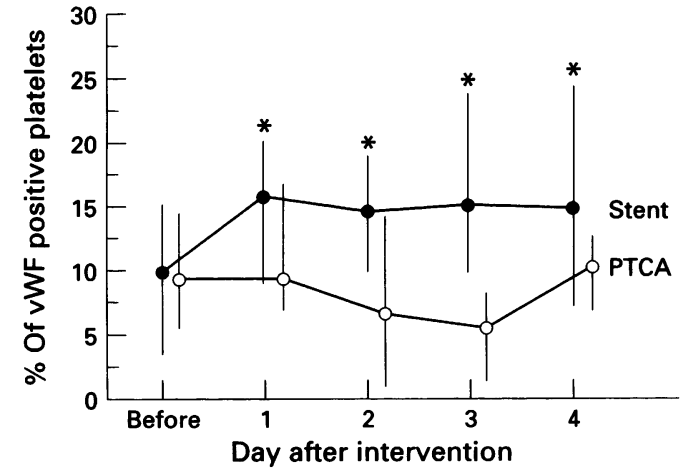

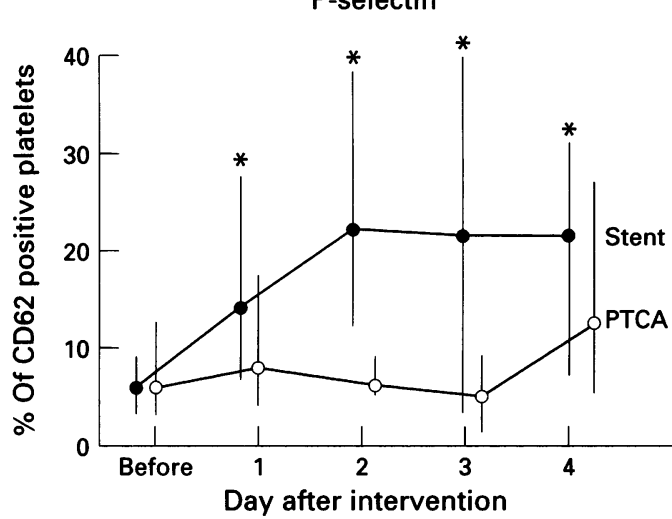

Figure $4 \quad \alpha$-Degranulation of circulating platelets in patients undergoing stent placement and PTCA. Surface expression of $P$-selectin was used as marker of degranulation of $\alpha$-granules. Graphs show surface exposure of $P$-selectin on circulating platelets in patients after coronary stent implantation $(n=30)(0)$ or elective balloon angioplasty $(n=30)$ (O). An asterisk indicates significance compared with starting values before intervention (day 1 to $4, P<0.01$ ).

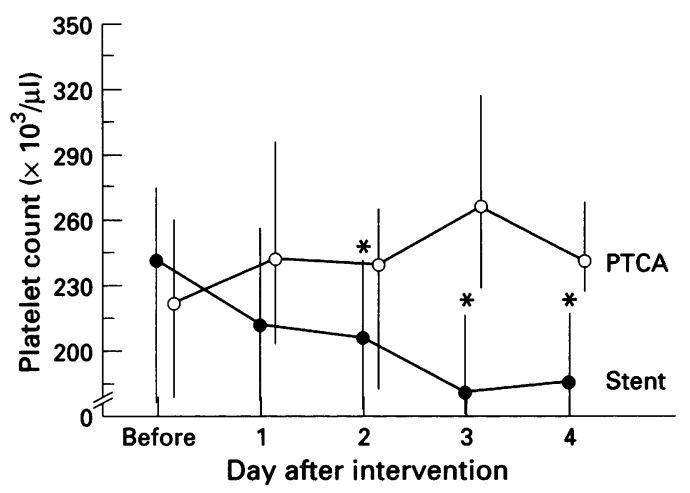

Figure 5 Peripheral platelet count in patients undergoing stent placement and PTCA. Graphs show time course of peripheral platelet count in patients after coronary stent implantation $(n=30)$ (O) or elective balloon angioplasty $(n=30)(\mathrm{O})$. An asterisk indicates significance compared with starting values before intervention (day 2 to $4, P<0.01$ ).

diameter stenosis before, and balloon/vessel ratio were not different in the two groups (table 3). In the PTCA group the diameter of the treated vessel was smaller and the degree of residual stenosis after the intervention was significantly higher than in the stent group (table 3). Within the observation period none of the patients had an acute ischaemic event that required repeat angioplasty. Twenty six of 30 patients undergoing stenting and 27 of the PTCA group were on long term aspirin treatment (table 4). Similarly, antianginal treatment before the procedure did not differ significantly between the two study groups (table 4). In the post-interventional observation time ( 4 days) both groups were receiving similar antiplatelet or $\beta$ blocker therapy (table 4). There were major differences between groups in the doses of heparin given (table 4).

\section{PLATELET FUNCTION}

Fibrinogen receptor function

Fibrinogen binding to platelets increased significantly above starting values the day after stent placement and remained raised for four 
days (fig 2). No significant change in fibrinogen binding was observed in the angioplasty (PTCA) group (fig 2). Similar results were found for anti-LIBS1 binding with increased anti-LIBS1 immunofluorescence signals above baseline values on days 2 and 3 whereas no significant change in LIBS 1 surface expression was found in the angioplasty (PTCA) group (fig 2). The increase in fibrinogen binding and LIBS1 surface exposure after stent implantation was not due to altered surface expression of glycoprotein IIb-IIIa complexes because binding of anti-CD41 remained unchanged throughout the observation period in both groups of patients (fig 2).

\section{von Willebrand factor binding}

As described above for fibrinogen receptor function, the percentage of platelets positive for von Willebrand factor significantly increased above starting values the day after coronary stenting and remained raised thereafter (fig 3). No change in von Willebrand factor binding to circulating platelets was found in the angioplasty group (fig 3 ).

\section{$\alpha$-Degranulation}

After coronary stenting degranulation of platelet P-selectin increased above starting values peaking at day 2 to 4 (fig 4 ). In contrast, no change in P-selectin surface expression was noted in the PTCA group (fig 4).

\section{Peripheral platelet count}

The day after coronary stenting the peripheral platelet count dropped below pre-stent values and remained decreased throughout the observation period (fig 5). No significant change in platelet count was noted in patients undergoing PTCA (fig 5).

\section{Discussion}

The present data show that coronary stenting with subsequent strict anticoagulation results in enhanced platelet activation. The major findings of this study are: (1) After coronary stent implantation fibrinogen receptor activity, von Willebrand factor binding, and surface expression of $\mathrm{P}$-selectin on circulating platelets is increased for days after the procedure. (2) The peripheral platelet count decreases after coronary stenting. (3) No significant change in peripheral platelet function and platelet count was found in patients undergoing angioplasty without stenting. These findings indicate that significant changes in platelet membrane glycoproteins occur in patients with coronary stent implantation. Platelet activation after coronary stenting coincides with a decrease in peripheral platelet count, suggesting increased sequestration of hyperactive circulating platelets. Enhanced platelet activation might be of pathophysiological importance in development of subacute stent thrombosis.

EFFECTS OF CORONARY STENTING ON

FIBRINOGEN RECEPTOR ACTIVITY

We found that fibrinogen receptor activity is significantly increased for days in patients after coronary stenting but not after balloon angioplasty (PTCA). Thus platelets circulate in a hyperreactive state after coronary stenting. Since fibrinogen receptor on platelets has a central role in platelet aggregation and thrombus formation ${ }^{1415-20}$ this may contribute to the risk of subacute stent thrombosis. Although the present study does not provide direct evidence, this assumption is supported by studies showing that patients with increased platelet activation before coronary angioplasty are at increased risk of acute ischaemic events after the procedure. ${ }^{26}{ }^{27}$ Moreover, antagonism of platelet fibrinogen receptor during angioplasty when the risk of coronary thrombosis is increased was shown to reduce acute coronary events significantly. ${ }^{34}$

\section{EFFECTS OF CORONARY STENTING ON VON} WILLEBRAND FACTOR BINDING

As well as enhanced fibrinogen receptor activity, we also found increased binding of von Willebrand factor to platelets after stent implantation: no detectable change in von Willebrand factor binding was found in patients undergoing PTCA. Since interaction of von Willebrand factor with platelets is crucial for platelet adhesion ${ }^{15} 1835$ the increase in von Willebrand factor binding to platelets implies that platelets circulate in a hyperadhesive state after coronary stenting. Thrombotic plug formation requires von Willebrand factor for two reasons: the glycoprotein is necessary for platelet adhesion to subendothelium and it is also necessary as a carrier for the procoagulant factor VIII molecule, which serves as an essential cofactor in factor $\mathrm{Xa}$ generation. ${ }^{35}$ We therefore speculate that the increased platelet binding of von Willebrand factor in coronary stent patients might enhance both platelet adhesion to the injured vessel wall and the procoagulant activity of circulating platelets.

\section{EFFECTS OF CORONARY STENTING ON}

$\alpha$-DEGRANULATION

P-selectin associated with the platelet membrane was used as marker for platelet degranulation. We found that surface expression of $P$-selectin on platelets was significantly increased after stenting. Thus coronary stenting is associated with an increased granule secretion and liberation of biologically potent platelet-stored compounds which might trigger biochemical mechanisms involved in restenosis as suggested previously. ${ }^{27}$ This includes release of growth factors such as platelet-derived growth factor (PDGF) or tumour growth factor that have been shown to initiate proliferation of smooth muscle cells and fibroblasts and thus have been implicated in the pathophysiology of restenosis after angioplasty. ${ }^{36}$

\section{PATHOPHYSIOLOGICAL CONSIDERATIONS}

Several factors that might have an impact on platelet function may account for the differences between the two patient groups: (1) prolonged and intensified antithrombotic therapy, 
(2) degree of vascular injury at the puncture site after angioplasty, (3) contact between circulating blood and an artificial surface, and (4) bleeding complications.

Because heparin has been shown to induce platelet activation in vitro and in vivo ${ }^{37} 38$ the enhanced platelet activity described in stent patients might be at least partially due to prolonged administration of high doses of heparin. Comparative studies using different anticoagulation regimens may help to clarify this. Furthermore, in our patients we performed coronary stent implantation because of a suboptimal immediate result after PTCA. Thus enhanced platelet activation after stenting might be a consequence of increased vessel injury at the plaque. We and others showed that the atherosclerotic lesion is a major source of platelet activation during PTCA. ${ }^{30}$ Although it is the least likely factor, the contact of circulating blood with the artificial surface of stents might trigger activation of the haemostatic system.

STUDY LIMITATIONS

The study of platelet function is always hampered by the possibility of artefactual platelet activation in vitro during blood sampling or further processing. In our study these variables were kept constant in all the individuals investigated. The reproducibility of the platelet assay was confirmed by evaluation of samples obtained from healthy controls on the day of patient evaluation. The platelet assay described here has been shown to be useful in evaluating platelet function in various diseases. ${ }^{28-32}$ We did not use fixed samples since we (unpublished observation) and others ${ }^{23}$ found that the immunoreactivity of platelet membrane glycoproteins was significantly decreased after fixation. Moreover, the fixative paraformaldehyde increases platelet degranulation. ${ }^{23}$

The present study was designed to evaluate platelet function in patients undergoing coronary stenting who were treated with conventional anticoagulation. At present we are not able to draw definite conclusions about what causes platelets to become activated in patients with coronary stents. Specifically, we cannot rule out that differences in angiographic results (for example, less obvious opening up of a stenosis) may be partly due to the observed differences in platelet activation in both groups of patients.

THERAPEUTIC IMPLICATIONS AND CONCLUSION Platelets play a central part in acute coronary thrombotic events. ${ }^{12}{ }^{13}$ The results that we describe question the effectiveness of currently applied antithrombotic regimens in coronary stent patients. The increase in platelet activation after coronary stenting emphasises the need for potent antiplatelet regimens in patients undergoing coronary stenting. Platelet membrane glycoproteins are increasingly becoming the target of novel antiplatelet drugs. Fibrinogen receptor antagonism in high risk PTCA procedures has been shown to reduce early ischaemic complications. ${ }^{34}$
Moreover, recent experimental data suggest that pharmacological interference in the interaction of von Willebrand factor with platelets inhibits thrombotic plug formation in vivo. ${ }^{35}$ Thus the changes in specific platelet membrane glycoproteins described here may help to develop new antithrombotic strategies in patients with stent implantation.

This study was supported by grants from the Deutsche Forschungsgemeinschaft $(\mathrm{Ga} 381 / 2-1)$ and from Johnson \& Johnson Interventional Products, Hamburg, Germany. We thank Caroline Bogner, Kathrin Gloth, and Corinna Kraft for expert technical assistance.

1 Herrmann HC, Buchbinder M, Clemen MW, Fischman $\mathrm{D}$, Goldberg S, Leon MB, et al. Emergent use of balloon, Goldberg S, Leon MB, et al. Eming for faile balloonneous transluminal coronary angioplasty. Circulation neous transluming:

2 Kastrati A, Schömig A, Dietz R, Neumann FJ, Richardt G. Time course of restenosis during the first year after Time course of restenosis during the first year after
emergency coronary stenting. Circulation. 1993;87: emergency

3 Schömig A, Kastrati A, Dietz R, Rauch B, Neumann FJ, Katus $\mathrm{HH}$, et al. Emergency coronary stenting for dissection during percutaneous transluminal coronary angioplasty: angiographic follow-up after stenting and after repeat angioplasty of the stented segment. $\mathcal{F ~} \mathrm{Am} \mathrm{Coll}$ Cardiol 1994;23:1053-60.

4 Sigwart U, Urvan P, Golf S, Kaufmann U, Imbert C, Fischer A, et al. Emergency stenting for acute occlusion after coronary balloon angioplasty. Circulation 1988;78 $1121-7$

5 Schömig A, Kastrati A, Mudra H, Blasini R, Schühlen $\mathrm{H}$, Klauss V, et al. Four-year experience with Palmaz-Schatz stenting in coronary angioplasty complicated by dissection with threatened or present vessel closure. Circulation 1994;90:2716-24.

6 Serruys PW, de Jaegere P, Kiemeneij F, Magaya C, Rutsch W, Heyndrickx G, et al. A comparison of balloonexpandable-stent implantation with balloon angioplasty in patients with coronary artery disease. $N \mathrm{Engl} \mathcal{F} \mathrm{Med}$ in patients with coro

7 Fischman DL, Leon MB, Baim DS, Schatz RA, Savage $\mathrm{MP}$, Detre $\mathrm{K}$, et al. A randomized comparison of coronary-stent placement and balloon angioplasty in the nary-stent placement and balloon angioplasty in the
treatment of coronary artery disease. $N$ Engl $f$ Med 1994;331:496-501.

8 Topol EJ. Caveats about elective coronary stenting. $N$ Engl f Med 1994;331:539-41.

9 Schatz RA, Baim DS, Leon M, Ellis SG, Goldberg S, Hirshfeld JW, et al. Clinical experience with the PalmazSchatz coronary stent. Initial results of a multicente study. Circulation 1991;83:148-61.

10 Haude M, Erbel R, Issa H, Straub U, Rupprecht HJ, Treese $\mathrm{N}$, et al. Subacute thrombotic complications after intracoronary implantation of Palmaz-Schatz stents. $A m$ Heart $\mathcal{F}$ 1993;126:15-22.

11 Schatz AS, Baim DS, Leon M, Ellis SG, Goldberg S, Hirshfeld JW, et al. Clinical experience with PalmazSchatz coronary stent. Circulation 1991;83:148-61.

12 Harker LA. Role of platelets and thrombosis in mechanisms of acute occlusion and restenosis after angioplasty. Am f Cardiol 1987;60:20B-28B.

13 Fuster V, Badimon L, Cohen M, Ambrose JA, Badimon JJ, Chesebro J. Insights into pathogenesis of acute ischemic syndromes. Circulation 1988;77:1213-20.

14 George JN, Nurden AT, Phillips DR. Molecular defects in interactions of platelets with the vessel wall. $N$ Engl f Med 1984;311:1084-98.

15 McEver RP. The clinical significance of platelet membrane glycoproteins. Hematol/Oncol Clin N Am 1990;4:87-103.

16 Becker RC. Antiplatelet therapy in coronary heart disease. Arch Pathol Lab Med 1993;117:89-96.

17 Gershlick AH. Principles of platelet inhibitor therapywhere we stood in 1993. Eur Heart $\mathcal{f} 1994 ; 15: 149-55$.

where we stood in 1993. Eur Heart $\mathcal{F}$ 1994;15:149-55.
18 Ruggeri ZM. New insights into mechanisms of platelet adhesion and aggregation. Sem Hematol 1994;31:229-39.

19 Phillips DR, Charo IF, Parise LV, Fitzgerald LA. The platelet membrane glycoprotein IIb-IIIa complex. Blood platelet membra

20 Plow EF, Ginsberg MH. Cellular adhesion. GPIIb-IIIa as a prototypic adhesion receptor. In: Coller BS, ed. Progress in hemostasis and thrombosis. Philadelphia: Saunders, $1989 ; 117-56$

21 Leung L and Nachman R. Molecular mechanisms of platelet aggregation. Ann Rev Med 1986;37:179-86.

22 Shattil SJ, Cunningham M, Hoxie JA. Detection of activated platelets in whole blood using activation-dependent monoclonal antibodies and flow cytometry. Blood 1987;70:307-15

23 Abrams C, Shattil SJ. Immunological detection of activated platelets in clinical disorders. Thromb Haemost 1991 65:467-73.

24 Rinder CS, Mathew JP, Rinder HM, Bonan J, Ault AK Smith BR. Modulation of platelet surface adhesion receptors during cardiopulmonary bypass. Anesthesiology 1991;75:563-70

25 Scharf RE, Tomer A, Mrzec UM, Teirstein PS, Ruggeri 
ZM, et al. Activation of platelets in blood perfusing angioplasty-damaged coronary arteries. Flow cytometric detection. Arterioscl Thromb 1992;12:1475-87.

26 Tschoepe D, Schultheiß HP, Kolarov P, Schwippert B, Dannehl K, Nieuwenhuis HK, et al. Platelet membrane activation markers are predictive for increased risk of acute ischemic events after PTCA. Circulation 1993;88: acute isch $37-42$.

27 Nurden AT, Macchi L, Bihour C, Durrieu C, Besse P, Nurden P. Markers of platelet activation in coronary Nurden $P$. Markers of platelet activation in coronary

28 Gawaz M, Fateh-Moghadam S, Pilz G, Gurland HJ Werdan K. Severity of multiple organ failure but not of sepsis correlates with irreversible platelet degranulation. sepsis correlates with ir
Infection 1995;23:16-27.

29 Gawaz MP, Dobos G, Späth M, Schollmeyer P, Gurland HJ, Mujais SK. Impaired function of platelet membrane glycoprotein IIb-IIIa in end-stage renal disease. $\mathcal{f} \mathrm{Am} \mathrm{Soc}$ Nephrol 1994;5:36-46.

30 Gawaz MP, Mujais SK, Schmidt B, Gurland HJ. Plateletleukocyte aggregation during hemodialysis. Kidney Int 1994;46:489-95.

31 Gawaz M, Ott I, Reininger AJ, Neumann FJ. Effects of magnesium on platelet aggregation and adhesion Magnesium modulates surface expression of glycoproteins on platelets in vitro and ex vivo. Thromb Haemost 1994;72:912-8. 32 Gawaz M, Neumann FJ, Ott I, Schiessler A, Schömig A. with direct angioplasty. Circulation 1996;93:229-37.

33 Ginsberg MH, Frelinger AL, Lam SCT, Forsyth J,
McMillan R, Plow EF, et al. Analysis of platelet aggregation disorders based on flow cytometric analysis of platelet membrane glycoprotein IIb-IIIa with conformation specific monoclonal antibodies. Blood 1990;76: 2017-23.

34 The EPIC Inverstigators: Use of a monoclonal antibody directed against the platelet glycoprotein IIb/IIIa receptor in high-risk coronary angioplasty. $N$ Engl f Med 1994;

35 Weiss HJ. von Willebrand factor and platelet function. In: Ruggeri ZM, Fulcher CA, Ware J, eds. Progress in vascular biology, hemostasis, and thrombosis. Ann NY Acad Sci biology, hemostasis,

36 Libby P, Schwartz D, Brogi E, Tanaka H, Clinton SK. A cascade model for restenosis. A special case of atherosclerosis progression Circulation 1992;86:III-47-III-52.

37 Salzman EW, Rosenberg RD, Smith $M H$, Lindon $\mathrm{NN}$, Favreau L. Effects of heparin and heparin fractions on platelet aggregation. $f$ Clin Invest 1980;65:65-73.

38 Landolfi R, DeCandia E, Rocca B, Ciabattoni G, Antinori $A$, Masetti $R$, et al. Effects of unfractionated and low molecular weight heparins on platelet thromboxane biosynthesis "in vivo". Thromb Haemost 1994;72:942-6.

39 Neumann FJ, Ott I, Gawaz M, Puchno G, Schömig A Neutrophil and platelet activation at balloon-infrared coronary artery plaque in patients undergoing angioplasty. $\mathcal{F}$ Am Coll Cardiol 1996;27:819-24.

40 Krupski WC, Bass A, Cadroy Y, Kelly AB, Harker LA Hanson SR. Antihemostatic and antithrombotic effects of monoclonal antibodies against von Willebrand factor in nonhuman primates. Surgery 1992;112:433-9. 